\title{
LOAD-intensity and time-under-tension of exercises for men who have Achilles tendinopathy (the LOADIT trial): a randomised feasibility trial
}

Fatmah Hasani ${ }^{1,2^{*}}$ (D, Terry Haines ${ }^{3}$, Shannon E. Munteanu ${ }^{4,5}$, Peter Schoch ${ }^{6,7,8}$, Bill Vicenzino ${ }^{9}$ and Peter Malliaras ${ }^{1}$

\begin{abstract}
Background: One potential reason for disparate outcomes of exercise for Achilles tendinopathy is poor knowledge about whether exercise parameters (i.e. different exercise doses) influence outcome. Whether parameters that are important for tendon adaptation influence clinical outcomes in Achilles tendinopathy has not been investigated. Therefore, this research aimed to assess the feasibility of conducting a fully powered randomised trial to investigate the efficacy of different load-intensity and time-under-tension exercise parameters for Achilles tendinopathy.

Methods: A factorial four-arm, randomised trial. Forty-eight male participants (18-70 years old) with mid-portion Achilles tendinopathy ( $\geq 3$ months) were recruited. Participants were randomly allocated to high (6 repetition maximum) or low intensity (18 repetition maximum) exercise, performed with either high ( $6 \mathrm{~s}$ per cycle) or low ( $2 \mathrm{~s}$ per cycle) time-under-tension. Participants performed 12-weeks of standing and seated calf raise exercises three times per week in a gym setting using a Smith machine. One session per week was supervised (via videoconference). Primary feasibility outcomes (recruitment and retention rate, exercise adherence and fidelity [i.e. time-under-tension, volume, load intensity], incidence of adverse events, health care use and productivity cost) were collected weekly. Means and standard deviations were determined for parametric data, medians and interquartile range for non-parametric continuous data, and frequency counts for discrete data.

Results: Total recruitment (76\%) and retention (90\%) rates were high. Exercise adherence ranged from 45 to $63 \%$ and fidelity ranged from 8 to $83 \%$ across the groups. Thirty-one participants reported 64 adverse events over the 3 months. Twenty-one participants (70\%) reported mild events. Participants reported reduced presenteeism more than absenteeism.

\footnotetext{
* Correspondence: fatmah.hasani@monash.edu

'Physiotherapy Department, School of Primary and Allied Health Care, Monash University, Frankston, Melbourne, Victoria 3199, Australia

${ }^{2}$ Physiotherapy Department, Security Forces Hospital, Riyadh 11481, Kingdom of Saudi Arabia

Full list of author information is available at the end of the article
}

(c) The Author(s). 2021 Open Access This article is licensed under a Creative Commons Attribution 4.0 International License, which permits use, sharing, adaptation, distribution and reproduction in any medium or format, as long as you give appropriate credit to the original author(s) and the source, provide a link to the Creative Commons licence, and indicate if changes were made. The images or other third party material in this article are included in the article's Creative Commons licence, unless indicated otherwise in a credit line to the material. If material is not included in the article's Creative Commons licence and your intended use is not permitted by statutory regulation or exceeds the permitted use, you will need to obtain permission directly from the copyright holder. To view a copy of this licence, visit http://creativecommons.org/licenses/by/4.0/. The Creative Commons Public Domain Dedication waiver (http://creativecommons.org/publicdomain/zero/1.0/) applies to the data made available in this article, unless otherwise stated in a credit line to the data. 
(Continued from previous page)

Conclusions: A fully powered trial is feasible. The proposed trial design and interventions demonstrated acceptable recruitment and retention rates and safety profile. However, exercise fidelity and adherence to the gym-based intervention was not acceptable. Strategies to improve intervention adherence and fidelity should be considered in future trials.

Trial registration: Australian New Zealand Clinical Trials Registry, ACTRN12618001315202. Registered retrospectively on August 6th, 2018.

Keywords: Achilles tendinopathy, Rehabilitation, Exercise parameters

\section{Clinical messages}

- Conducting a fully powered randomised trial to determine the efficacy of different load-intensity and time-under-tension exercise parameters for Achilles tendinopathy is feasible.

- Strategies designed to improve exercise adherence and fidelity are necessary prior to progressing to a fully powered trial.

- The findings provide important preliminary information regarding treatment effect sizes of the interventions described.

\section{Background}

Mid-portion Achilles tendinopathy is a common musculoskeletal condition characterised by localised Achilles tendon load-related pain and dysfunction [1]. The pain mechanisms in tendinopathy are not clear but are thought to involve local nociception [2]. The etiology of tendinopathy is complex and multifactorial [3], but imbalance between the load demands placed on the tendon and its capacity to remodel is considered a major factor [4]. Both athletes and sedentary people can be affected, and many suffer profound and longstanding impairment of activities such as walking and running $[5,6]$.

Although calf loading exercise is promoted as an evidence-based treatment, there is no clear guidance from the research about which exercise approach is optimal [7-9]. This may be because; i) the efficacy of different exercise parameters have not been adequately investigated; ii) exercise approaches are poorly reported so hard to compare; iii) exercise adherence is either not reported or reported with untrustworthy measures; and iv) the specific exercise approach may not matter as much as other factors (e.g. psychological factors such as conceptualisation of pain) $[6,8,10,11]$.

A sensible first step and the focus of the trial reported here was to develop evidence for whether exercise parameters influence outcomes in Achilles tendinopathy. Many parameters can be influenced in exercise prescription to have specific effects on the musculotendinous unit, including load-intensity (e.g. repetition maximum [RM], maximal voluntary contraction), volume (repetitions and sets), and time under tension per contraction (repetition duration) [12]. A systematic review investigating exercise response (i.e. adaptative outcomes such as tendon stiffness) in healthy Achilles and patellar tendons concluded that load-intensity is a key determinant of tendon tissue adaptation to load, and the type of contraction (e.g. eccentric versus concentric) did not influence adaptation [13]. Load-intensity results in greater tendon tissue strain which deforms tendon cells and triggers anabolic cell signalling [14]. There is also evidence that longer duration contractions at the same intensity result in greater Achilles tendon adaptation [15], most likely because there is time-dependent transmission of external load to the tendon cytoskeleton and cells. Whether parameters that are important for tendon adaptation such as load-intensity and duration of contraction (or time-under-tension) influence clinical outcomes in Achilles tendinopathy has not been investigated.

The primary aim of this study was to determine the feasibility of conducting a fully powered randomised trial to determine the efficacy of different load-intensity and time-under-tension exercise parameters for Achilles tendinopathy. Maximising and monitoring exercise adherence and fidelity are integral to the validity of conclusions that can ultimately be made from such a fully powered trial, so we chose to use regular telehealth to efficiently monitor (and encourage) these factors. The key outcomes were (i) rate of participant recruitment, conversion, and retention, (ii) ability to perform the interventions per-protocol (adequate exercise fidelity and adherence based on weekly videoconference assessment), (iii) incidence and type of adverse events, (iv) use of rescue medication and cointerventions, and (v) feasibility of future economic evaluation. The secondary aim was to provide estimates of the variability of key outcomes. Outcomes were informed by a recent international consensus on core outcomes for tendinopathy [16] and included pain and disability, satisfaction, physical activity, health-related quality of life, psychological measures and plantarflexor function. In terms of plantarflexor function capacity we assessed maximal voluntary contraction, rate of torque development and force steadiness because these may be impaired among individuals with Achilles tendinopathy $[17,18]$. 


\section{Methods}

\section{Design}

LOADIT (LOAD- Intensity and Time-under-tension) is a four-arm, factorial randomised pilot trial. The two factors, each with two levels, are load-intensity (determined by RM, the maximum mass that can be lifted for a given number of repetitions) and time-under-tension (determined by seconds). Participants were randomly allocated into one of four groups: $6 \mathrm{RM}$ with $2 \mathrm{~s}$ repetitions; $6 \mathrm{RM}$ with $6 \mathrm{~s}$ repetitions; $18 \mathrm{RM}$ with $2 \mathrm{~s}$ repetitions; or 18 RM with $6 \mathrm{~s}$ repetitions group (Fig. 1). The methods are described in the published protocol [19]. The study was reported in accordance with the CONSORT extension for randomised pilot and feasibility trials [20] and the TIDieR guide [21]. The protocol was registered (August 2018; ACTRN 12618001315202. The trial was approved by the Human Research Ethics Committee at Monash University (ethics number 2018-1366-20,711).

\section{Study population}

Participants were included if they were male, aged between 18 to 70 years with a history of mid-portion Achilles tendon pain in either or both legs for $\geq 12$ weeks, and scored $\leq 75$ on the Victorian Institute of Sports Assessment - Achilles questionnaire (VISA-A). Men were the focus because of evidence that tendon adaptation to exercise (and therefore possibly clinical outcomes) may be confounded by sex [22]. The clinical diagnosis was based on the clinical presentation, physical examination and ultrasound imaging done by practicing physiotherapist $(\mathrm{FH})$. Exclusion included a history of Achilles tendon rupture, surgery in the

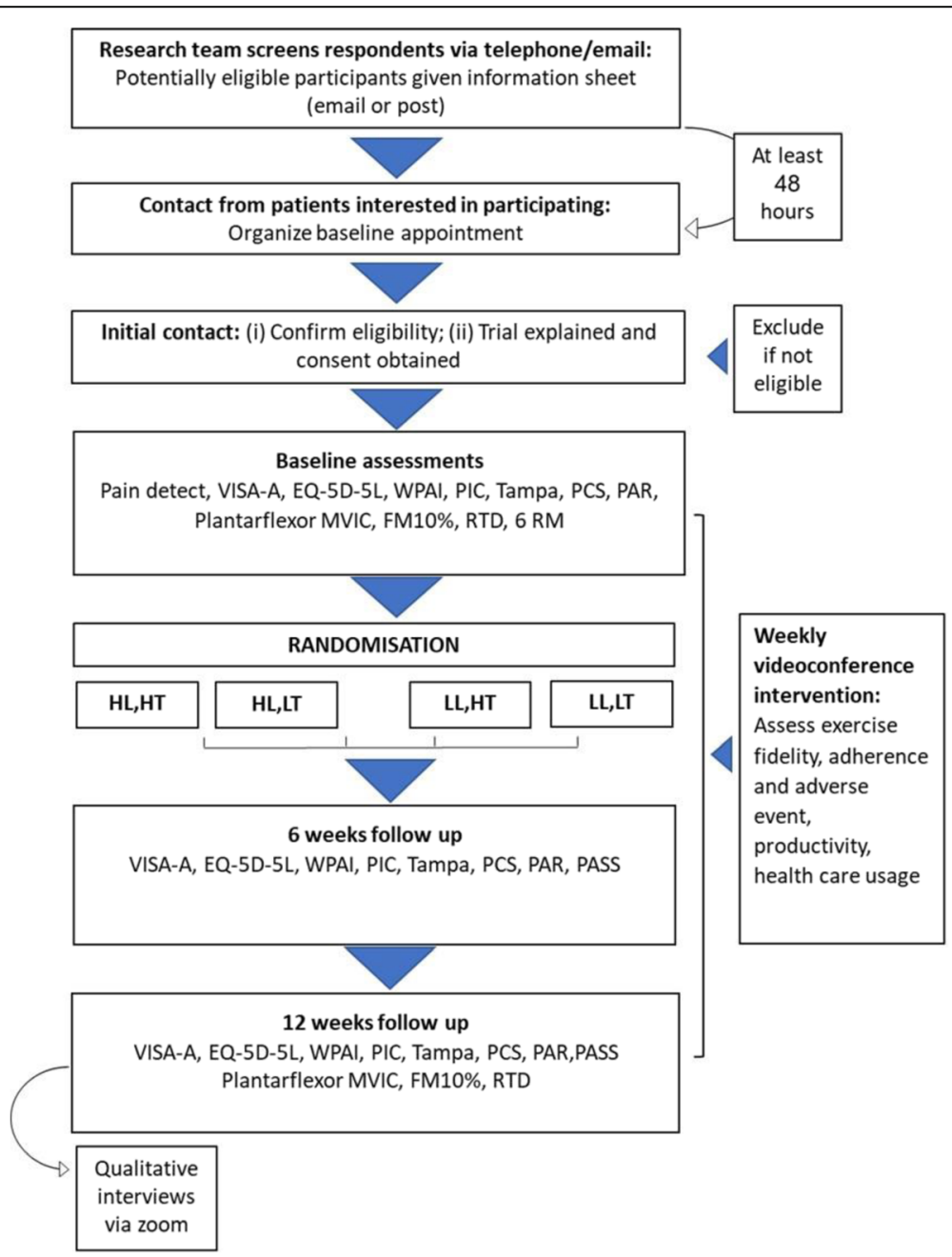

Fig. 1 Trial profile. Abbreviation: HL, High load; HT, High time-under-tension; LL, Low load; LT, Low time-under-tension; VISA-A, Victorian Institute of Sports Assessment - Achilles; EQ-5D-5L, Health-related Quality of Life; WPAI, Work Productivity and Activity Impairment; PIC, Patient Impression of Change; PCS, Pain Catastrophising Scale; PAR, Physical Activity Recall questionnaire; PASS, Patient-Acceptable Symptom State instrument for satisfaction; MVIC, Maximal Voluntary Isometric Contraction; FM10\%, Force match at 10\%; RTD, Rate of Torque Development; RM, repetition maximum 
symptomatic lower limb(s) or any health conditions that may interfere with the execution of the exercise interventions. Participants were also excluded if they had had an injection or received strength exercise treatment for their Achilles tendon pain within the last 3 months.

\section{Recruitment and setting}

Participants were recruited via social media (i.e. Facebook, Twitter), and by posting study information on relevant internet websites (e.g. sports clubs and forums), as well as referral from health professionals in Melbourne. All screening assessments and data collection were conducted at a single centre (Monash University, Melbourne, Victoria, Australia) between July 2018 and May 2019. Responders to the advertisements were asked to provide their contact number. They were contacted and screened via the telephone by research assistants who also provided trial information. Those who confirmed interest in the study (either at the time of the telephone call or by re-initiating contact with the researcher after the initial call) were invited to attend a screening visit to confirm their eligibility. All participants provided oral and written informed consent before joining the trial.

\section{Randomisation and blinding}

A randomisation sequence with permuted blocks of variable size was created using an online randomisation service (Sealed Envelope Ltd., London) and then concealed in opaque sealed envelopes by a researcher who was not in contact with participants $(\mathrm{TH})$. The treating physiotherapists and participants were not blinded. Each participant received a scripted explanation of the trial which included that there is uncertainty about whether any of the exercise interventions would be superior. The participants were assigned to intervention by the same investigator (PM). The investigator $(\mathrm{FH})$ who administered and collected the secondary outcomes and the statistician were blinded to group allocation.

\section{Exercise interventions}

Participants performed four sets of unilateral standing and seated isotonic calf raise exercise to load the ankle plantarflexor complex (both sides, one leg at a time), three times per week for 12 weeks, with standardised rest times (90 s between sets). The 12-week endpoint was chosen because it has been shown to be a sufficient timeframe for exercise to have a clinically meaningful effect on Achilles tendinopathy pain and function [23]. Both isotonic exercises were performed in a Smith machine at a local gymnasium (gym membership was provided free of charge to participants, if required). A practicing physiotherapist monitored one session per week (via videoconferencing software [Zoom $\left.{ }^{\circ}\right]$ ) and provided exercise progression and technique feedback. In each session, the physiotherapists rated the exercise fidelity criteria as achieved or not achieved per our protocol i.e. prescribed number of repetitions, sets, RM and speed of contraction [19]. During the weekly telehealth session, exercise adherence and fidelity (prior to providing feedback), adverse events, use of co-interventions, and productivity data were collected. Participants were taught calf raise exercise technique [19] using parameters specific to their group allocation (Table 1) and the exercises were externally paced using a metronome (via smartphone application). Participants were instructed to exercise to volitional failure and how to progress and regress exercise based on difficulty with the exercise and pain experienced. The instruction to participants was that they should feel that they cannot do any more repetitions when they complete the set. A range of \pm one repetition and pain with load $<5$ out of 10 on numerical rating scale is allowed. After the baseline testing of the repetition maximum, exercise intensity was adjusted down by $10 \%$ in all groups to reduce the risk of muscle soreness related to commencement of unaccustomed exercise. Further exercise details are provided in additional file 1 and the protocol [19].

Participants were provided with education related to tendon pain mechanisms and acceptable levels of pain during exercise and activity. Participants were advised to consume up to four g/day pain-relieving medication [24] (i.e. paracetamol), if required. Participants received advice to gradually increase walking, running and sports activity if Achilles tendon pain during these activities was not beyond level 5 out of 10 on an 11-point numerical pain rating scale (NPRS) $0=$ no pain, $10=$ worst pain imaginable) [25]. They were also advised it was acceptable for pain after sport activities to temporarily increase as long as it returned to baseline levels on a tendon loading test such as single-leg submaximal hop or single leg calf raise, within approximately $24 \mathrm{~h}$.

\section{Outcome measures Primary outcomes}

Rate of conversion, recruitment, and retention The conversion rate was the proportion of people who consented divided by those who met the criteria. The recruitment rate was the number of participants recruited per month. Retention was the proportion of recruited participants who completed the 12-week outcome assessment. The conversion and retention success criteria were $\geq 20$ and $80 \%$ respectively.

Exercise adherence and fidelity Adherence was the proportion of prescribed exercise sessions completed or 
Table 1 Calf exercise dosage for each group

\begin{tabular}{|c|c|c|c|c|}
\hline & \multicolumn{2}{|l|}{ High Load } & \multicolumn{2}{|l|}{ Low Load } \\
\hline & $\begin{array}{l}\text { with High TUT } \\
\text { (Group 1) }\end{array}$ & $\begin{array}{l}\text { with Low TUT } \\
\text { (Group 2) }\end{array}$ & $\begin{array}{l}\text { with High TUT } \\
\text { (Group 3) }\end{array}$ & $\begin{array}{l}\text { with Low TUT } \\
\text { (Group 4) }\end{array}$ \\
\hline Load intensity & $6 \mathrm{RM}$ & $6 \mathrm{RM}$ & $18 \mathrm{RM}$ & $18 \mathrm{RM}$ \\
\hline Repetition & 6 & 6 & 18 & 18 \\
\hline Sets & 4 & 4 & 4 & 4 \\
\hline Contraction time/rep & $\begin{array}{l}3 \mathrm{~s} \text { concentric } \\
3 \mathrm{~s} \text { eccentric }\end{array}$ & $\begin{array}{l}1 \mathrm{~s} \text { concentric } \\
1 \mathrm{~s} \text { eccentric }\end{array}$ & $\begin{array}{l}3 \text { s concentric } \\
3 \text { s eccentric }\end{array}$ & $\begin{array}{l}1 \mathrm{~s} \text { concentric } \\
1 \mathrm{~s} \text { eccentric }\end{array}$ \\
\hline Rest in between reps & No & No & No & No \\
\hline Contraction time per set & $36 s$ & $12 \mathrm{~s}$ & $108 \mathrm{~s}$ & $36 s$ \\
\hline Total contraction time & $288 \mathrm{~s}$ & $96 s$ & $864 \mathrm{~s}$ & $288 \mathrm{~s}$ \\
\hline Volitional muscular failure & Yes & Yes & Yes & Yes \\
\hline Range of motion & $\begin{array}{l}0^{\circ} \text { to } 15^{\circ} \mathrm{DF} \\
0^{\circ} \text { to } 50^{\circ} \mathrm{PF}\end{array}$ & $\begin{array}{l}0^{\circ} \text { to } 15^{\circ} \mathrm{DF} \\
0^{\circ} \text { to } 50^{\circ} \mathrm{PF}\end{array}$ & $\begin{array}{l}0^{\circ} \text { to } 15^{\circ} \mathrm{DF} \\
0^{\circ} \text { to } 50^{\circ} \mathrm{PF}\end{array}$ & $\begin{array}{l}0^{\circ} \text { to } 15^{\circ} \mathrm{DF} \\
0^{\circ} \text { to } 50^{\circ} \mathrm{PF}\end{array}$ \\
\hline
\end{tabular}

Abbreviations: TUT time-under-tension, RM repetition maximum, TUT time-under-tension, DF dorsiflexion, $P F$ planter flexion, $S$ seconds

attempted of the total of 36 and was expressed as the frequency and percentage. Fidelity was the proportion of weeks (out of 12) where participants achieved adequate fidelity in each parameter i.e. tempo per contraction [time-under-tension], volume [repetitions and sets] and intensity [failure \pm one repetition]. It was also expressed as frequency and percentage. Achieving $\geq 66 \%$ in adherence and fidelity was deemed a success criterion for the trial. We are not aware of any established minimum level of exercise fidelity for a trial like this but reasoned that exercise fidelity that was below this threshold of $66 \%$ (whether across all groups or only in a proportion of groups) may impact on the effectiveness of the protocol exercise parameters and limit the certainty of any conclusions.

Incidence of adverse events An adverse event was defined as any unintended symptom associated with the study which may or may not be related to the intervention [26]. The frequency (number of participants and number of cases), nature (e.g. sprained ankle, a muscle tear or tendon pain worsening), and severity (mild $[<48$ h], moderate [up to 7 days], or severe [ $>7$ days or requiring medical attention]) were recorded at the weekly telehealth session. Individuals experiencing adverse events were managed by the research team or triaged to an appropriate medical facility.

Use of co-interventions The frequency of the use of paracetamol medication and other co-interventions was recorded.

Feasibility of future economic evaluation These costs were divided into the following:
- The direct intervention costs: This included the gym membership (estimated 15 AUD per week), physiotherapy treatment and participant screening time (estimated rate 150 AUD per hour). Other direct cost for co-interventions were calculated based on number of days the co-intervention $\times$ market price or by estimating the once off cost of the health product.

- The indirect cost or productivity cost included the absenteeism (time loss from work due to Achilles tendinopathy) and presenteeism (productivity loss while at work due to Achilles tendinopathy) were assessed using the Health-related work productivity questionnaire (WPAI) [27]. Absenteeism cost was calculated by multiplying this percentage score $\times$ the average wage rate in Australia (estimated at 45 AUD per hour) according to Australian Bureau of Statistics figures [28]. The costs of productivity loss due to presenteeism were calculated by multiplying the percentage of rating scale indicating the degree of health problem affected productivity while working score $\times$ number of hours actually worked per week) $\times$ 45 AUD.

\section{Secondary outcomes}

Patient-reported outcomes Nine patient-reported outcomes were included: (i) The severity of pain and disability were assessed using the VISA-A [29]; (ii) The worst pain level experienced in the last week with an NPRS (11- point scale, $0=$ no pain, $10=$ worst imaginable pain); (iii) Patient Impression of Change (PIC) which is a 7-point Likert scale including two questions; 1) "How would you describe your Achilles tendon pain now, compared to before you began the treatment?" and 2) "How would you describe your ability to perform 
physical activities (such as walking, running, housework) now, compared to before you began the treatment?" [30]; (iv) Patient-Acceptable Symptom State instrument [31] which involved a yes or no response to two questions: "Currently are you satisfied with your condition?", and "Would you recommend this treatment to another person who has Achilles pain?"; (v) Health-related quality of life was measured using the 5-level EQ-5D version (EQ. 5D $5 \mathrm{~L}$ index value and overall health state [VAS]); (vi) Physical activity using 7-day Recall Physical Activity Questionnaire [32]; (vii) Fear of movement or re-injury: Kinesiophobia was measured with the Tampa Scale for Kinesiophobia (TSK) [33]; (viii) Pain catastrophising was measured using the Pain Catastrophising Scale (PCS) [34], and (ix) the painDETECT questionnaire for neuropathic pain was only assessed at baseline [35].

Plantarflexor strength tests A custom-built ankle dynamometer (participants seated with $50^{\circ}$ knee flexion) was used to assess plantarflexor torque during maximal voluntary isometric contraction, rate of torque development and force matching (see additional file 2 for details). Force matching involved maintaining ankle plantarflexor force equivalent to $10 \%$ of their maximal voluntary isometric contraction with visual feedback on a screen $1.5 \mathrm{~m}$ in front of them.

\section{Sample size}

We made a pragmatic decision that we would be able to achieve our feasibility aim by recruiting 48 participants to be randomised into one of four factorial arms $(n=12$ per trial arm as a rule of thumb recommended by Julious) [36].

\section{Data management and analysis}

Entered data were checked for accuracy by two study investigators $(\mathrm{FH}, \mathrm{PM})$. Statistical analysis was undertaken on coded data (group allocation concealed). Data from the most painful side were analysed for people with bilateral Achilles pain. SPSS (version 25, IBM Corp., Armonk, NY, USA) was used for statistical analysis. Means and standard deviations were determined for parametric data, medians and interquartile range for non-parametric continuous data, and frequency counts for discrete data. Mean change and standardised response mean $(\mathrm{SRM}=$ mean change over time within group/ standard deviation of changes scores over time) from baseline to 6 and 12 weeks with 95\% confidence intervals were calculated to provide an estimate of the within group effect size for all secondary outcomes. The SRM magnitude was interpreted (as per Hopkins) as very large when $\geq 1.2$, moderate when $\geq 0.6$, and small when $\geq 0.2$ [37]. The PIC 7-point Likert scale was dichotomised for analyses ("very much improved" and "improved" represents treatment effectiveness).

The maximal voluntary isometric contraction torque data $(\mathrm{Nm})$ were extracted directly from PowerLab (AD Instruments Corp, Dunedin, NZ) whereas the rate of torque development data $(\mathrm{Nm} / \mathrm{s})$ and force match data were exported to Excel (Microsoft Corporation, Redmond, WA). The peak rate of torque development (0$50 \mathrm{Nm}$ scale window) was analysed using a customwritten software program (rehabtools.org, Sunshine Coast, Australia). This method used the peak value obtained from an iterative $50 \mathrm{~ms}$ averaging window, which has been shown to be highly reliable [38]. Whilst it is a shorter duration than that used in other clinical populations such as people living with stroke [39] this window was shown to be most reliable in our pilot analysis and is less susceptible to a plateau effect from rapid contractions with rise durations shorter than longer windows [39]. The coefficient of variation of torque for the $15 \mathrm{~s}$ sampling window was used to represent fluctuations in force-matching (ratio of standard deviation to the mean torque).

Patterns of missing data were analysed using Little's Missing Completely at Random test [40]. Data substitution was not applied for missing data given this was a feasibility study with a small sample. However, an effort was made to collect the patient-reported outcomes data especially for those who discontinued the intervention.

\section{Results}

The sample consisted of 48 men, aged 20 to 65 years (mean age $43.2 \pm 10.4$ years). The duration of symptoms ranged from 3 to 240 months (two outliers of 240 months, median $=24$ ). The BMI ranged from 20 to 45 $\mathrm{kg} / \mathrm{m}^{2}$. None of the participants reported neuropathic pain (Table 2). From 1043 initial contacts, 86 people were screened in-person, 63 were eligible and 48 consented (Fig. 2).

\section{Primary outcomes \\ Rate of conversion, recruitment, and retention}

Both conversion and retention rate were acceptable. The conversion rate was $76 \%(48 / 63)$ (Fig. 2). The recruitment rate ranged from 3 to 20 per month over the 6 months recruitment window (Fig. 3) because the Facebook strategy was intermittent (i.e. stopped for 4 months during holiday periods). Forty-one (85\%) participants were recruited via Facebook (total spend \$9052.91 AUD; average spend of \$221 AUD per person recruited) and the remaining $(7[15 \%])$ via clinical networks and the community.

Five participants did not complete the study (Fig. 2) giving a retention rate of $90 \%$ (43/48). Four participants dropped out because of the burden of the intervention, 
Table 2 Participant characteristics at baseline for each group. Values are mean (SD) unless otherwise noted

\begin{tabular}{|c|c|c|c|c|}
\hline & \multicolumn{2}{|l|}{ High Load } & \multicolumn{2}{|l|}{ Low Load } \\
\hline & $\begin{array}{l}\text { with High TUT } \\
(n=12)\end{array}$ & $\begin{array}{l}\text { with Low TUT } \\
(n=12)\end{array}$ & $\begin{array}{l}\text { with High TUT } \\
(n=12)\end{array}$ & $\begin{array}{l}\text { with Low TUT } \\
(n=12)\end{array}$ \\
\hline Age, years & $42.0(11.4)$ & $43.0(11.3)$ & $41.6(7.2)$ & $46.3(11.9)$ \\
\hline Height, $\mathrm{cm}$ & $177.8(6.2)$ & $176.6(10.3)$ & $178.1(8.2)$ & $175.0(8.2)$ \\
\hline Mass, kg & $89.0(17.9)$ & $97.0(18.1)$ & $84.6(17.1)$ & $94.5(13.7)$ \\
\hline Body mass index, $\mathrm{kg} / \mathrm{m}^{2}$ & $28.0(4.6)$ & $31.1(5.3)$ & $26.6(4.4)$ & $30.6(6.4)$ \\
\hline \multicolumn{5}{|l|}{ Employment ${ }^{a}$} \\
\hline Full-time & $10(83)$ & $8(67)$ & $10(83)$ & $9(75)$ \\
\hline Part-time & 0 & $1(8)$ & 0 & $1(8)$ \\
\hline Casual & $1(8)$ & $1(8)$ & 0 & $1(8)$ \\
\hline Self-employed & 0 & $2(17)$ & $1(8)$ & $1(8)$ \\
\hline Student & $1(8)$ & 0 & $1(8)$ & 0 \\
\hline Duration of symptoms, months ${ }^{b}$ & $11.0(39)$ & $54.0(83)$ & $18.0(30)$ & $12.0(36)$ \\
\hline Dominant side, - right $^{\mathrm{a}}$ & $11(92)$ & $11(92)$ & $8(67)$ & $10(83)$ \\
\hline Presentation, unilateral/ bilateral ${ }^{\mathrm{a}}$ & $7(58) / 5(42)$ & $6(50) / 6(50)$ & $4(33) / 8(67)$ & $6(50) / 6(50)$ \\
\hline Achilles tendon AP diameter, $\mathrm{mm}^{c}$ & $6.9(1.3)$ & $7.8(1.9)$ & $7.3(2.2)$ & $8.5(3.1)$ \\
\hline Prior exercise treatment, yes ${ }^{a}$ & $3(25)$ & $4(33)$ & $6(50)$ & $8(67)$ \\
\hline Classified Achilles pain quality ${ }^{a, d}$ & $7(58)$ & $10(83)$ & $9(75)$ & $9(75)$ \\
\hline \multicolumn{5}{|l|}{ Intensity of Achilles pain ${ }^{\text {a }}$} \\
\hline Mild & $3(25)$ & $3(25)$ & $2(17)$ & $4(33)$ \\
\hline Moderate & $9(75)$ & $5(42)$ & $8(66)$ & $4(33)$ \\
\hline Severe & 0 & $4(33)$ & $2(17)$ & $4(33)$ \\
\hline VISA-A & $55.3(13.4)$ & $44.8(18.1)$ & $46.0(15.8)$ & $54.7(9.8)$ \\
\hline Pain Detect & $10.0(5.2)$ & $12.2(6.1)$ & $10.0(6.0)$ & $10.0(5.0)$ \\
\hline
\end{tabular}

Abbreviations: TUT time-under-tension, VISA-A Victorian Institute of Sports Assessment-Achilles questionnaire. ${ }^{\mathrm{a}} \mathrm{n}$ (\%). ${ }^{\mathrm{b}}$ Median (interquartile range). ${ }^{\mathrm{c}}$ Measured using b-mode sonography. ${ }^{d}$ Measured using pain mapping app

and one participant dropped out due to severe back pain. Between 86 and $98 \%$ of outcome data were collected at each timepoint.

\section{Exercise adherence and fidelity}

Exercise adherence and fidelity data are presented in Table 3. The proportion of adherence to the supervised sessions was 71 to $92 \%$ and total adherence was 49 to 68\% (1-2 sessions completed out of 3 per week). Fidelity varied substantially between criteria, with highest fidelity (58 to 83\%) seen for the volume criterion. The timeunder-tension criterion averaged $<66 \%$ across all groups. Fidelity was lower for high-intensity groups (Fig. 4). In general, the success rate (66\%) was not reached for both adherence and fidelity outcome.

\section{Incidence of adverse events}

There were between six and eight participants per group who experienced an adverse event and a total of 64 reported adverse events over the 3 months (Table 3 ). Twenty-one participants (70\%) reported mild adverse events that included Achilles pain, headache, and pain in other areas [shoulder, wrist, back]). Eight participants (17\%) reported moderate adverse events (included back, anterior knee and shin pain) that occurred more frequently in the high-intensity groups (21\% versus $13 \%$ ). There was only one serious adverse event that was not related to the interventions (back pain that required surgery).

\section{Use of co-interventions}

There were similar rates of co-intervention use between groups (Table 3). Common co-interventions included myotherapy, acupuncture, and topical non-steroidal anti-inflammatory agents (i.e. diclofenac gel). Four to six participants in each group reported using paracetamol for their associated pain, during the 12 weeks of intervention.

Table 3. Feasibility outcomes. Values are n (\%) unless otherwise noted.

\section{Feasibility of future economic evaluation}

Over the three-month study period, the direct cost was 1050 AUD and indirect cost was 37 AUD per participant. This included costs associated with participants who withdrew or missed sessions. The 3 months gym membership cost was 180 AUD per participant. Average presenteeism was valued at 412 AUD per participant 


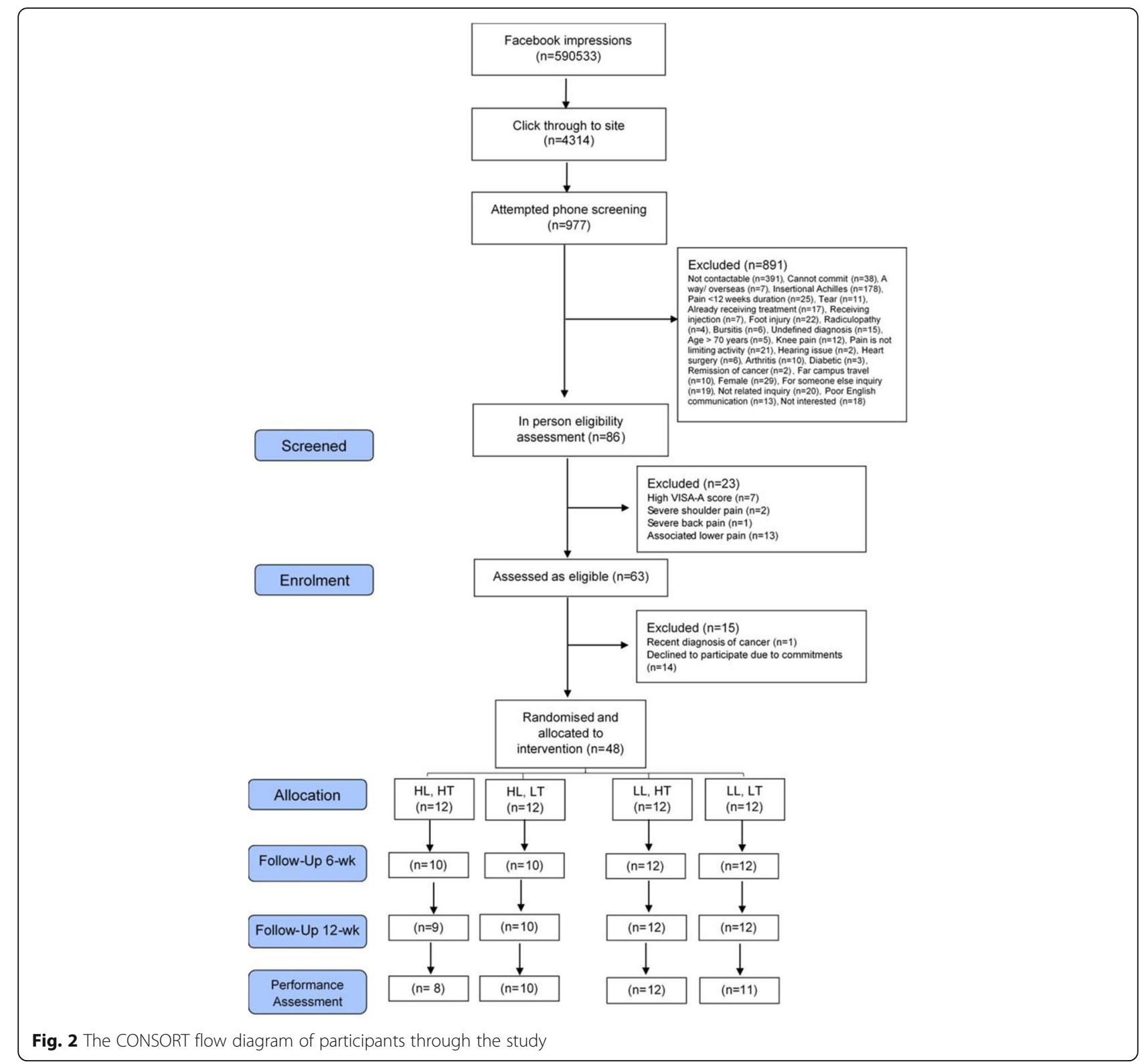

over the three-month study period. Only one participant reported absenteeism $(8 \mathrm{~h})$ due to their Achilles tendinopathy, which equated to a cost of 765 AUD.

\section{Secondary outcomes}

\section{Patient-reported outcomes}

All groups displayed improvement in self-reported outcome measures during the study (Table 4). At 12 weeks, the mean improvement in VISA-A scores was between 26 to 40 points (Fig. 5). The worst pain over the last week decreased by an average of 3 to 4 points. More than $75 \%$ of participants reported an improvement in pain and function and satisfaction with condition postintervention.

\section{Plantarflexor strength tests}

All groups displayed improvement in all strength tests (Table 5). The magnitude of mass lifted increased by about $25 \%$ in seated and $10 \%$ in the standing positions (Fig. 6).

\section{Discussion}

This pilot randomised trial has demonstrated that the interventions are safe (only one unrelated serious adverse event), and the rate of conversion, recruitment, and retention were acceptable. Adherence to the gym-based intervention was acceptable for the weekly telehealth supervised sessions but not for the two non-supervised sessions. Exercise fidelity varied substantially between criteria and was unsatisfactory 


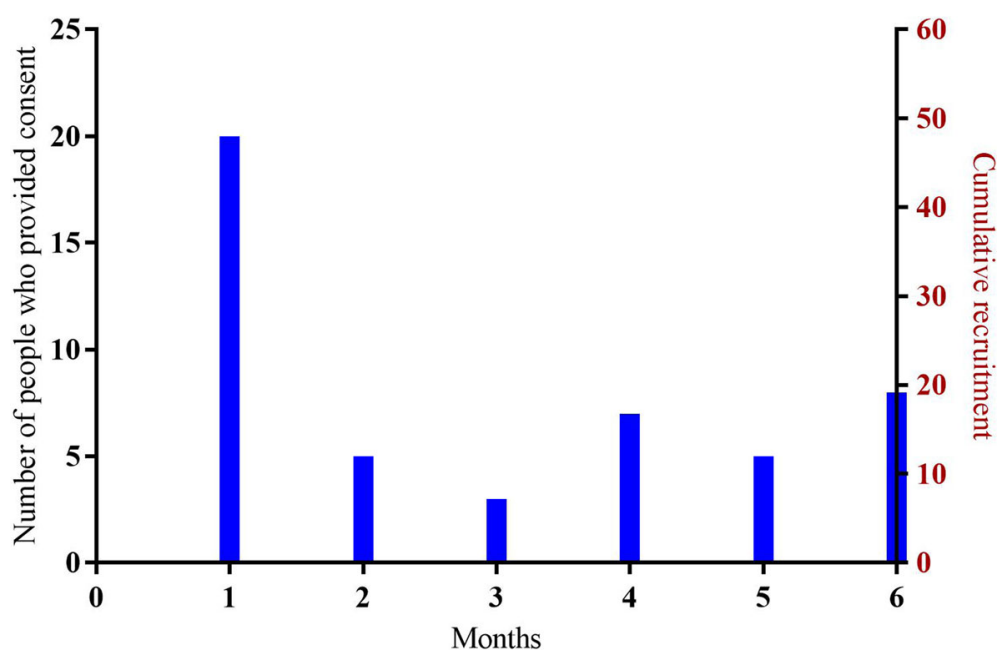

Fig. 3 Monthly and cumulative recruitment to the feasibility trial

Table 3 Feasibility outcomes. Values are n (\%) unless otherwise noted

\begin{tabular}{|c|c|c|c|c|}
\hline & \multicolumn{2}{|l|}{ High Load } & \multicolumn{2}{|l|}{ Low Load } \\
\hline & with High TUT & with Low TUT & with High TUT & with Low TUT \\
\hline Session time duration in minutes ${ }^{a}$ & $43.4(12.2)$ & $39.0(6.1)$ & $53.0(7.3)$ & $37.1(7.0)$ \\
\hline \multicolumn{5}{|l|}{ Adherence $^{b}$} \\
\hline Number of zoom sessions completed / 12 & $11(92)$ & $9(71)$ & $11(92)$ & $10(79)$ \\
\hline Number of home sessions completed / 36 & $21(58)$ & $18(49)$ & $21(58)$ & $25(68)$ \\
\hline \multicolumn{5}{|l|}{ Fidelity of exercise dose parameters in seated } \\
\hline Time-under-tension & $5(42)$ & $5(42)$ & $6(50)$ & $7(58)$ \\
\hline Volume & $7(58)$ & $8(67)$ & $8(67)$ & $10(83)$ \\
\hline Load intensity & $6(50)$ & $1(8)$ & $8(67)$ & $8(67)$ \\
\hline \multicolumn{5}{|l|}{ Fidelity of exercise dose parameters in standing } \\
\hline Time-under-tension & $5(42)$ & $3(25)$ & $6(50)$ & $6(50)$ \\
\hline Volume & $7(58)$ & $7(58)$ & $8(67)$ & $7(58)$ \\
\hline Load intensity & $5(42)$ & $4(33)$ & $9(75)$ & $7(58)$ \\
\hline No. of participants who reporting adverse event & $8(67)$ & $8(67)$ & $8(67)$ & $6(50)$ \\
\hline \multicolumn{5}{|l|}{ Severity of adverse events ${ }^{c}$} \\
\hline Mild & $4(33)$ & $6(50)$ & $8(67)$ & $3(25)$ \\
\hline Moderate & $3(25)$ & $2(17)$ & 0 & $3(25)$ \\
\hline Severe & $1(8)$ & 0 & 0 & 0 \\
\hline Achilles related adverse events & $3(25)$ & $4(33)$ & $4(33)$ & $4(33)$ \\
\hline \multicolumn{5}{|l|}{ Severity of Achilles related adverse events } \\
\hline Mild & $3(25)$ & $4(33)$ & $4(33)$ & $3(25)$ \\
\hline Moderate & 0 & 0 & 0 & 0 \\
\hline Severe & 0 & 0 & 0 & 0 \\
\hline No. of participants who used co-interventions & $3(25)$ & $2(17)$ & $2(17)$ & $4(33)$ \\
\hline No. of participants using paracetamol & $4(33)$ & $5(42)$ & $4(33)$ & $6(50)$ \\
\hline Total paracetamol tablets used ${ }^{d}$ & $16(33)$ & $31(33)$ & $33(25)$ & $17(25)$ \\
\hline
\end{tabular}

Abbreviations: TUT time-under-tension. ${ }^{\text {a }}$ Mean (SD); ${ }^{b}$ Median (percentage); ${ }^{c}$ Mild: some discomfort noted but without disruption of daily life that goes within $24-$ 28 h; Moderate: discomfort enough to affect/reduce normal activity that goes within 3-5 days; Severe: complete inability to perform daily activities and lead a normal life and that requires medical intervention; ${ }^{d}$ tablet dose $=500 \mathrm{mg} ;$ 


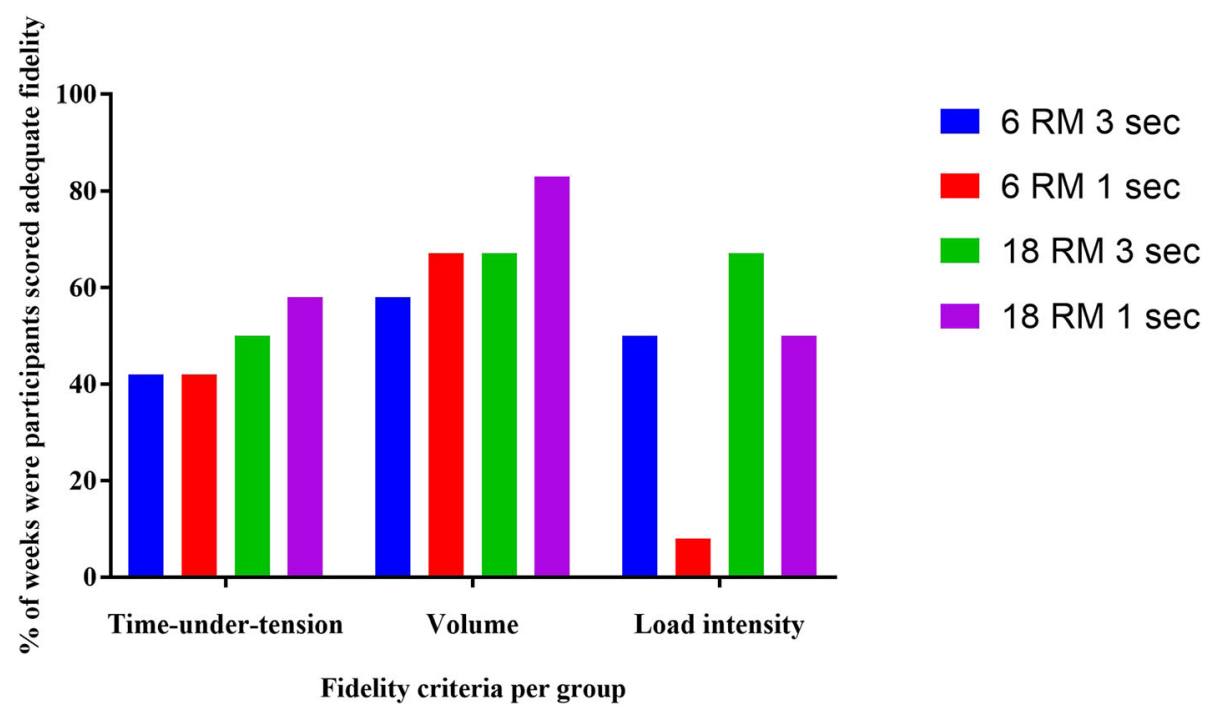

Fig. 4 Exercise fidelity of the individual exercise dose parameters for each participant per group

for the time-under-tension criterion across all groups. Prior to progressing to a fully powered trial, further work is necessary to identify and trial strategies to improve exercise adherence and fidelity. The major cost appeared to be related to provision of the intervention. Unlike other chronic pain conditions [41], the amount of time lost from work and productivity loss at work related to this condition was minimal, which raises the question whether economic evaluation is warranted in a fully powered trial.

Retention was $79 \%$ across the groups that exercised at high-intensity, compared to $100 \%$ in the low-intensity groups. We do not know whether this difference in dropout rate is related to the exercise interventions (e.g. people undertaking high load-intensity found it more difficult and were less likely to continue). There was a higher rate of moderate adverse events, based on inspection of estimates not significance testing, in the highintensity $(5 / 24=21 \%)$ versus low-intensity groups (3/ $24=13 \%$ ). Follow-up qualitative interviews did not identify any themes that may explain this observation (unpublished data). We took precautions to reduce muscle soreness from exercise (revising down exercise intensity for all groups initially).

Only one serious adverse event was reported during the study. A participant in the high load-intensity with lower time-under-tension group developed severe low back pain that required surgery. This adverse event did not occur whilst the participant was undertaking the exercise prescribed as part of this trial, and it is not possible to ascertain whether the prescribed exercise was a factor in this occurrence. Mild and anticipated Achilles related adverse events such as ankle sprain and tendon pain provocation were common and occurred with similar frequency in each group (25 to 33\%). It appears that overall, the interventions described in this study are safe.

Our interventions have similar characteristics to the 'heavy slow resistance training' intervention utilised by Beyer et al. [42]. Heavy slow resistance involves three sessions of gym-based calf loading exercise per week. There were, however, differences in reported exercise adherence between our pilot trial (49 to 68\%) and the Beyer et al. trial (92\% for heavy slow resistance). Discrepant adherence rates may be explained by methodological differences between the trials. First, Beyer et al. prescribed three 2-legged exercises (three exercises in total) which would have been less time consuming than the four exercise (2 on each limb) in our study. Second, the socio-geographical environment (Copenhagen versus Melbourne) may have influenced adherence (e.g. commute time to the gym or traffic congestion favouring Copenhagen). Third, the adherence data was recorded more frequently in our study (weekly by our physiotherapists from patient report during the telehealth sessions versus a single supervised session plus patient diaries in the Beyer study) which may have influenced accuracy by reduced recall bias [42]. Future studies could benefit from better understanding barriers to patients' exercise adherence, in order to identify and implement strategies to improve adherence across all trial groups, such as more supervised exercise sessions, either synchronously or asynchronously (e.g. via patients self-recording exercise sessions).

Exercise fidelity was important for ensuring that the exercise groups varied in the exercise parameters that were being compared including volume, intensity and time-under-tension. There was varied fidelity rate across 
Table 4 Patient-reported outcomes with change score and standardised response mean. Values are mean (SD) unless otherwise noted

\begin{tabular}{|c|c|c|c|c|}
\hline & \multicolumn{2}{|l|}{ High Load } & \multicolumn{2}{|l|}{ Low Load } \\
\hline & with High TUT & with Low TUT & with High TUT & with Low TUT \\
\hline \multicolumn{5}{|l|}{ Self-reported measures } \\
\hline \multicolumn{5}{|l|}{ Severity of pain using VISA-A ${ }^{a} / 100$} \\
\hline Baseline & $55.3(13.4)$ & $44.8(18.1)$ & $46.0(15.8)$ & $54.7(9.8)$ \\
\hline Week-6 & $69.3(14.8)$ & $65.2(16.7)$ & $63.2(16.8)$ & $68.5(14.0)$ \\
\hline Week-12 & $81.5(11.2)$ & $80.7(17.5)$ & $86.3(9.0)$ & $83.8(13.0)$ \\
\hline Change score at 6-weeks, $[95 \% \mathrm{Cl}]$ & $14.0[11,17]$ & $15.0[11,19]$ & $17.2[14,20]$ & $14.0[11,17]$ \\
\hline Change score at 12 -weeks, $[95 \% \mathrm{Cl}]$ & $22.0[19,25]$ & $22.4[19,25]$ & $40.3[37,43]$ & $29.2[26,32]$ \\
\hline SRM baseline-week 6 & 0.9 & 0.5 & 1.3 & 1.0 \\
\hline SRM baseline-week 12 & 1.4 & 0.6 & 2.2 & 2.1 \\
\hline \multicolumn{5}{|c|}{ Worst pain using Numerical Pain Rating Scale / $10^{\mathrm{b}}$} \\
\hline Baseline & $5.0(2.2)$ & $4.8(3.2)$ & $4.7(3.0)$ & $5.0(3.0)$ \\
\hline Week-6 & $2.4(2.5)$ & $2.2(1.0)$ & $3.1(2.2)$ & $3.3(2.2)$ \\
\hline Week-12 & $3.4(2.7)$ & $2.3(2.0)$ & $2.1(2.3)$ & $2.3(1.8)$ \\
\hline Change score at 6-weeks, [95\%Cl] & $-3.0[-4 .-2]$ & $-2.0[-4 .-1]$ & $-2.0[-4,1]$ & $-1.1[-2.1]$ \\
\hline Change score at 12-weeks, [95\%Cl] & $-2.1[-3,1]$ & $-4.0[-5,-2]$ & $-2.0[-5,-0.5]$ & $-2.5[-5,-1]$ \\
\hline SRM baseline-week 6 & -1.2 & -0.7 & -0.5 & -0.4 \\
\hline SRM baseline-week 12 & -1.1 & -0.9 & -0.8 & -0.9 \\
\hline \multicolumn{5}{|l|}{ EQ-5D-5L, Index c/ 1} \\
\hline Baseline & $0.71(0.10)$ & $0.71(0.17)$ & $0.72(0.10)$ & $0.74(0.10)$ \\
\hline Week-6 & $0.79(0.09)$ & $0.76(0.16)$ & $0.76(0.10)$ & $0.78(0.14)$ \\
\hline Week-12 & $0.84(0.11)$ & $0.88(0.14)$ & $0.84(0.11)$ & $0.87(0.12)$ \\
\hline Change score at 6-weeks, [95\%Cl] & $0.08[0.1,0.3]$ & $0.04[-0.2,0.3]$ & $0.02[-0.12,0]$ & $0.03[-0.2,3]$ \\
\hline Change score at 12 -weeks, $[95 \% \mathrm{Cl}]$ & $0.14[0.1,0.5]$ & $0.2[-0.1,0.3]$ & $0.12[-0.1,0.3]$ & $0.13[0,0.3]$ \\
\hline SRM baseline-week 6 & 0.8 & 0.2 & 0.2 & 0.3 \\
\hline SRM baseline-week 12 & 1.1 & 1.0 & 1.1 & 1.1 \\
\hline \multicolumn{5}{|l|}{ EQ-5D-5L, VAS ${ }^{d} / 100$} \\
\hline Baseline & $67.8(15.2)$ & $70.2(17.8)$ & $72.8(16.6)$ & $69.6(12.0)$ \\
\hline Week-6 & $82.2(8.5)$ & $75.3(9.4)$ & $80.0(8.3)$ & 75.7 (13.6) \\
\hline Week-12 & $83.4(13.2)$ & $82.6(15.5)$ & $82.3(10.3)$ & $74.0(11.5)$ \\
\hline Change score at 6-weeks, $[95 \% \mathrm{Cl}]$ & $15.0[12,18]$ & $6.4[5,8]$ & $7.0[4,10]$ & $6.0[4,8]$ \\
\hline Change score at 12 -weeks, $[95 \% \mathrm{Cl}]$ & $19.0[16,22]$ & $14.0[12,14]$ & $9.0[7,11]$ & $4.0[2,6]$ \\
\hline SRM baseline-week 6 & 0.9 & 0.6 & 0.4 & 0.8 \\
\hline SRM baseline-week 12 & 0.9 & 2.0 & 1.0 & 0.4 \\
\hline \multicolumn{5}{|l|}{ 7-Day Activity Recall e } \\
\hline Baseline & $1041(170)$ & $1322(257)$ & $1017(200)$ & $1303(296)$ \\
\hline Week-6 & $1071(241)$ & $1311(237)$ & 997 (194) & $1229(256)$ \\
\hline Week-12 & $837(555)$ & $1314(211)$ & $1046(175)$ & $1275(285)$ \\
\hline Change score at 6-weeks, $[95 \% \mathrm{Cl}]$ & $29.3[19,40]$ & $-11.0[-23,2]$ & $-20.0[-29,-11]$ & $74.0[-62,-86]$ \\
\hline Change score at 12 -weeks, $[95 \% \mathrm{Cl}]$ & $86.2[82,96]$ & $-3.0[-15,5]$ & $29.0[-29,-10]$ & $-28[-62,-86]$ \\
\hline SRM baseline-week 6 & 0.1 & 0 & 0 & 0 \\
\hline SRM baseline-week 12 & 0.3 & 0 & 0.2 & 0 \\
\hline
\end{tabular}

Tampa Scale for Kinesiophobia $\mathrm{f} / 68$ 
Table 4 Patient-reported outcomes with change score and standardised response mean. Values are mean (SD) unless otherwise noted (Continued)

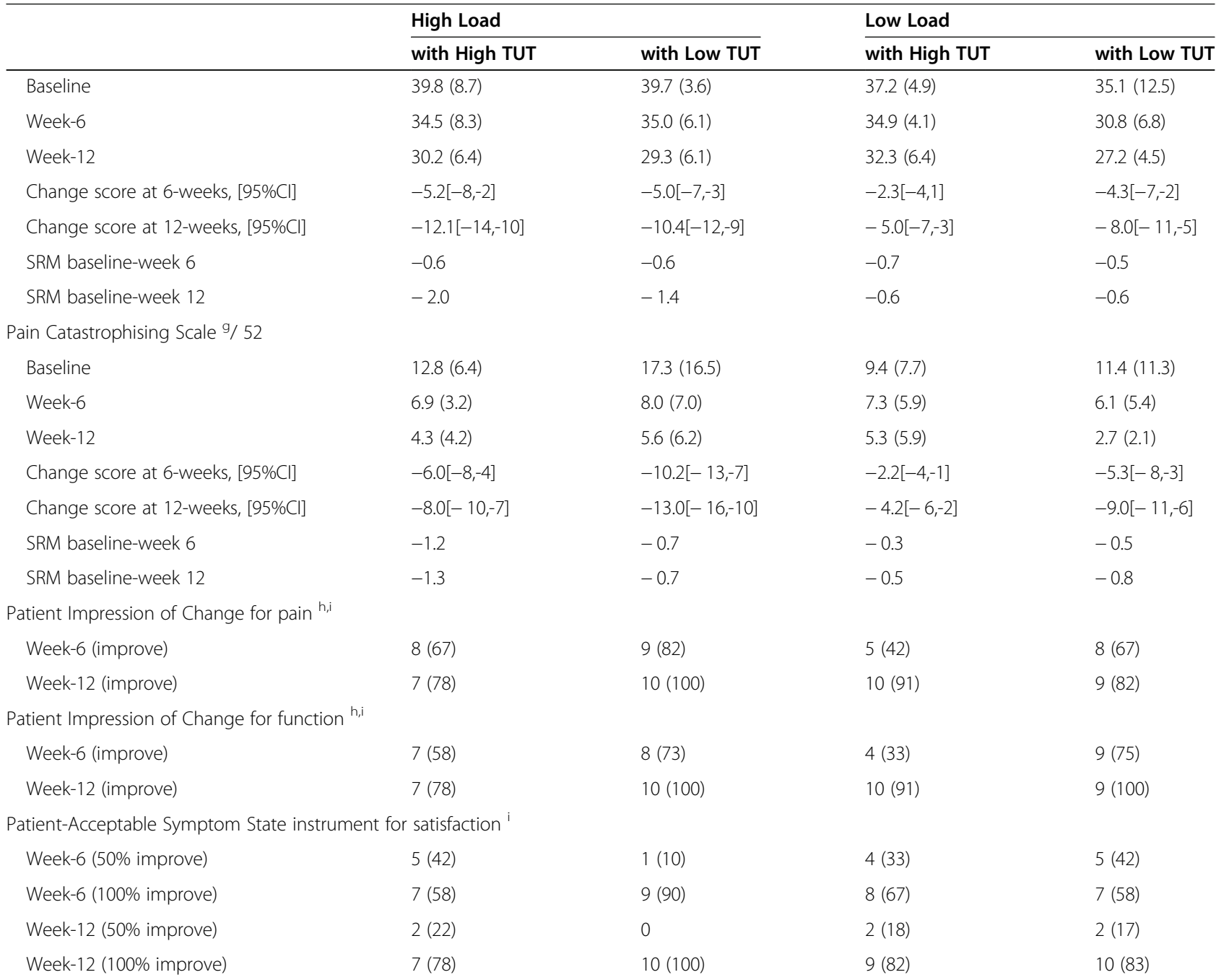

Abbreviations: ${ }^{\mathrm{a} S}$ Scores on the VISA-A range from 0 (worst Achilles symptoms) to 100 (no Achilles tendinopathy). ${ }^{\mathrm{b}}$ worst pain during the week scored on the NPRS range from 0 (no pain) to 10 (worst pain imaginable). 'Scores on the EQ-5D-5L Index Value range from <0 (worse than dead) to 0 (dead) to 1 (full health). ${ }^{\mathrm{d} S c o r e s}$

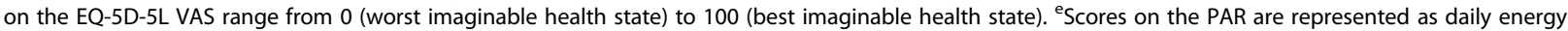
expenditure (kilocalories per day). ${ }^{\mathrm{f}}$ Tampa score ranges from 17 (no fear of movement) to 68 (greater fear of movement). ${ }^{9}$ Scores on CPS range from 0 (no pain) to 52 (higher levels of pain catastrophising). ${ }^{\mathrm{h}}$ dichotomised scores to "improved" and "not improved". 'n (\%)

all the trial groups with the lowest fidelity seen for the time-under-tension criterion (25 to 42\%). Adequate time-under-tension was achieved if calf raise tempo was judged by the telehealth rater (physiotherapist) to be in time with metronome (auditory cue) during the telehealth sessions. Errors related to poor internet connection and delayed or freezing video that may impact the rating, were reduced by re-rating any trials in which this was perceived by the rater. This criterion may have been too stringent because the overall time-under-tension may have been satisfactory even if there were timing violations for some of the repetitions. In future trials comparing different levels of time-under-tension, we recommend comparing total time-under-tension per set. Although they did not assess time-under-tension,
Sancho et al. recently reported exercise (calf raises and hopping) fidelity ranging from 22 to $64 \%$ for volume and load-intensity [43].

High-intensity groups had lower fidelity compared to low-intensity groups. This could be related to training until volitional failure. Utilising a repetition in reserve paradigm may be more appropriate [44] and can be considered in a future trial. Fidelity strategies may need to be targeted towards the high-intensity groups as they seem to have more difficulty performing the required load-intensity. This could be a practical issue i.e. participants lifting heavy weight, or fear issues.

At 12 weeks, there was an improvement in patientreported pain and function scores measured with the VISA-A questionnaire, ranging from 26 to 40 points. In a 


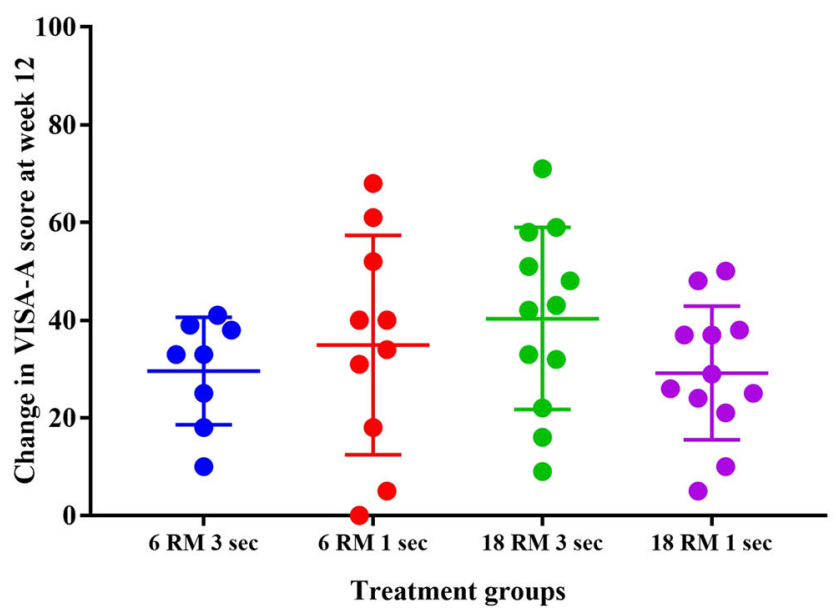

- 6 RM $3 \mathrm{sec}$

- $6 \mathrm{RM} 1 \mathrm{sec}$

- $18 \mathrm{RM} 3 \mathrm{sec}$

- $18 \mathrm{RM} 1 \mathrm{sec}$

Treatment groups

Fig. 5 Individual participants changes in VISA-A scores with the intervention

Table 5 Performance outcomes with change score and standardised response mean (mean \pm SD)

\begin{tabular}{|c|c|c|c|c|}
\hline & \multicolumn{2}{|l|}{ High Load } & \multicolumn{2}{|l|}{ Low Load } \\
\hline & with High TUT & with Low TUT & with High TUT & with Low TUT \\
\hline \multicolumn{5}{|c|}{ Ankle plantarflexion torque (Nm) } \\
\hline Baseline & $188.4(43.1)$ & $194.9(60.8)$ & $188.6(53.8)$ & $188.5(66.2)$ \\
\hline Week-12 & $225.8(32.9)$ & $220.0(42.8)$ & $204.9(58.0)$ & $206.8(40.0)$ \\
\hline Change score, $[95 \% \mathrm{Cl}]$ & $48.3[44,53]$ & $27.0[22,32]$ & $16.3[12,21]$ & $24.4[19,30]$ \\
\hline SRM baseline-week 12 & 1.4 & 0.8 & 1.0 & 0.6 \\
\hline \multicolumn{5}{|c|}{ Ankle plantarflexion rated of torque development (Nm/s) } \\
\hline Baseline & $644.5(235.3)$ & $637.4(326.6)$ & $635.9(215.8)$ & $557.1(197.5)$ \\
\hline Week-12 & $850.4(174.4)$ & $738.9(189.0)$ & $699.9(183.4)$ & $668.6(170.4)$ \\
\hline Change score, $[95 \% \mathrm{Cl}]$ & $232.0[220,244]$ & $134.0[122,146]$ & $64.0[54,74]$ & $153.0[143,163]$ \\
\hline SRM baseline-week 12 & 0.8 & 0.6 & 0.6 & 0.9 \\
\hline \multicolumn{5}{|c|}{ Plantarflexor coefficient of variation of torque } \\
\hline Baseline & $1.9(0.8)$ & $1.9(0.4)$ & $2.3(1.0)$ & $2.2(1.0)$ \\
\hline Week-12 & $1.6(0.2)$ & $1.6(0.9)$ & $1.9(1.0)$ & $1.7(1.0)$ \\
\hline Change score, $[95 \% \mathrm{Cl}]$ & $-0.7[-0.1,0]$ & $-0.3[-0.8,0.3]$ & $-0.5[-1.2,0.3]$ & $-0.5[-1.3,0.4]$ \\
\hline SRM baseline-week 12 & -0.9 & -0.3 & -0.6 & -0.3 \\
\hline \multicolumn{5}{|l|}{ Mass lifted in seated (kg) } \\
\hline Baseline & $54.5(20.2)$ & $38.3(23.4)$ & $45.8(10.2)$ & $56.3(17.2)$ \\
\hline Week-12 & $77.5(41.8)$ & $64.0(19.1)$ & $70.8(25.0)$ & $79.4(26.0)$ \\
\hline Change score, $[95 \% \mathrm{Cl}]$ & $15.0[11,18]$ & $28.0[24,31]$ & $37.0[34,39]$ & $24.2[21,28]$ \\
\hline SRM baseline-week 12 & 0.5 & 1.3 & 2.2 & 1.2 \\
\hline \multicolumn{5}{|l|}{ Mass lifted in standing (kg) } \\
\hline Baseline & $13.1(8.7)$ & $11.2(14.0)$ & $9.5(7.1)$ & $8.3(9.5)$ \\
\hline Week-12 & $27.4(14.1)$ & $18.0(12.0)$ & $16.2(11.4)$ & $22.1(23.3)$ \\
\hline Change score, [95\%Cl] & $14.0[11,16]$ & $9.3[-7,12]$ & $3.3[1,6]$ & $12.0[9,14]$ \\
\hline SRM baseline-week 12 & 1.0 & 1.0 & 0.2 & 0.7 \\
\hline
\end{tabular}




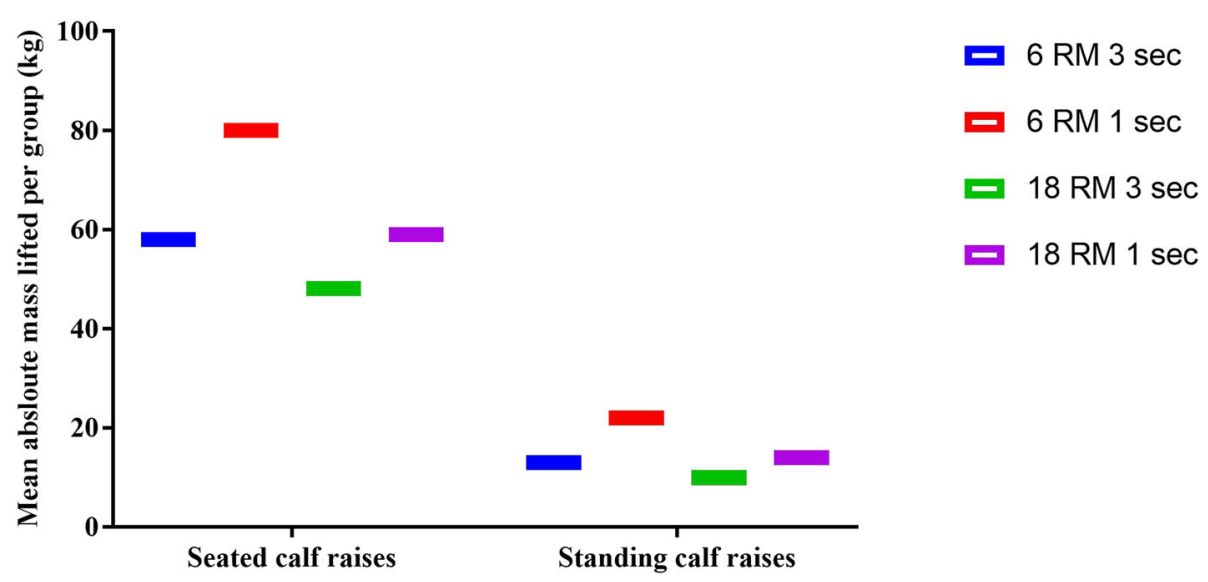

Fig. 6 Overall absolute mass lifted during the intervention

recent systematic review of 31 studies among individuals with Achilles tendinopathy undergoing a calf muscle loading program mean (SD) change in patient-reported pain and function (measured using the VISA-A questionnaire) was 21.1 (6.6) points [10]. Our findings are one to three standard deviations above this pooled mean. A clinically meaningful change is suggested to be 10-points [42, 45, 46] and this is also the Cochrane collaboration recommended minimal clinically important difference for a 100-point function scale [47]. However, our study did not include a control group, so the influence of natural history or placebo is not known. Other secondary outcomes also changed favourably in all groups. The improvements were likely to be clinically meaningful as the estimated effect size were moderate to large $\geq 0.6$. Although our three-month outcome is appropriate for our efficacy trial, longer term follow-up would eventually be needed to determine the long-term effects of our interventions.

Variability of the VISA-A outcome in our data can be used to estimate the sample size for a future fully powered randomised controlled trial. Ninety-four participants (i.e. 47 per group) would provide power of over $80 \%$ to detect an effect size of 10-points on the VISA-A questionnaire $[42,45,46]$ with the significance level set at $p<0.05$. A pooled standard deviation of 17.2 was derived from the $4 \mathrm{arms}$ in this pilot study. The sample size calculation assumes that intention to treat analysis is being applied so ignores non-adherence and drop-out.

This study has limitations. First, limiting recruitment to men reduces generalisability. This was justified in our trial because the exercise parameters being tested may have a differential effect on tissue adaptation and clinical outcomes between sexes [22]. Another limitation related to including only men is that our feasibility and pilot data (including the sample size estimate) may not extrapolate to women and this needs to be considered carefully in planning a fully powered trial. Second, although the outcome assessor was blinded to treatment allocation, participants and physiotherapists providing care via videoconference were not, so there is the risk of performance and detection bias. This was mitigated partly by expressing uncertainty to participants regarding potential comparative efficacy between groups. Preferences of participants or physiotherapists towards certain exercise parameters may still be an issue and we recommend assessing outcome expectations, or implementation of procedures to blind participants (and assessors) in future trials. Third, we recruited a majority of participants via social media and it is not certain whether they represent the range of individuals presenting for Achilles tendinopathy management in primary care. However, the age and severity profile (VISA-A scores) is similar to other studies also undertaken in Australia among individuals with Achilles tendinopathy [48].

\section{Conclusions}

The results of this study suggest that high and lowintensity and time-under-tension loading protocols are feasible and safe for individuals with mid-portion Achilles tendinopathy. Future trials should consider strategies to optimise exercise adherence and fidelity.

\section{Abbreviations}

RM: Repetition maximum; VISA-A: Victorian Institute of Sports Assessment Achilles questionnaire; MVIC: Maximal Voluntary Isometric Contraction; RTD: Rate of Torque Development; NPRS: Numerical Pain Rating Scale; PIC: Patient Impression of Change; WPAI: Work Productivity and Activity Impairment Questionnaire

\section{Supplementary Information}

The online version contains supplementary material available at https://doi. org/10.1186/s13102-021-00279-z.

Additional file 1. Load progression

Additional file 2. Ankle plantarflexor strength testing. 


\section{Acknowledgments}

We would like to acknowledge all participants, physiotherapists, and research assistants participated in this trial.

\section{Authors' contributions}

All authors (FH, TH, SEM, BV, PS and PM) contributed to the conception, design of the trial and interpretation the data. FH and PM conducted the data collection. FH and TH completed the data analysis. PM contributed to training and supervision of the physiotherapists involved on the trial. $\mathrm{FH}$ drafted the manuscript and all co-authors provided critical revisions to the clinical and intellectual content. All authors have read and approved the manuscript.

\section{Funding}

This research was funded by a grant from the International Mechanical Diagnosis and Therapy Research Foundation (IMDTRF). Funding source did not play a role in any aspects relating to the study design, data collection, data analysis and management, interpretation of data, writing of the report, or publication and dissemination of study findings.

\section{Availability of data and materials}

The datasets used and/or analysed during the current study are available from the corresponding author on reasonable request.

\section{Declarations}

\section{Ethics approval and consent to participate}

All experimental procedures have been approved by the Human Research Ethics Committee at Monash University (ethics number 2018-1366-20711) for study protocol version 3 dated 10/07/2018 and all supporting documents. Any significant modification to the study protocol will require a formal amendment. Written informed consent was obtained from all participants.

\section{Consent for publication}

Not applicable.

\section{Competing interests}

PM is a member of the editorial board (Associate Editor) of this journal. Peter Schoch is a Faculty member of the McKenzie Institute Australia and McKenzie Institute International and receives payment for teaching post graduate courses in the McKenzie Method of Mechanical Diagnosis and Therapy. He has no direct affiliation with the International Mechanical Diagnosis and Therapy Research Foundation. FH, TH, SEM and BV declare that they have no competing interests.

\section{Author details}

'Physiotherapy Department, School of Primary and Allied Health Care, Monash University, Frankston, Melbourne, Victoria 3199, Australia. ${ }^{2}$ Physiotherapy Department, Security Forces Hospital, Riyadh 11481, Kingdom of Saudi Arabia. ${ }^{3}$ School of Primary and Allied Health Care, Faculty of Medicine, Nursing, and Health Sciences, Monash University, Frankston, Victoria 3199, Australia. ${ }^{4}$ Discipline of Podiatry, School of Allied Health, Human Services and Sport, College of Science, Health and Engineering, La Trobe University, Melbourne, Victoria 3086, Australia. ${ }^{5}$ La Trobe Sport and Exercise Medicine Research Centre, School of Allied Health, Human Services and Sport, College of Science, Health and Engineering, La Trobe University, Melbourne, Victoria 3086, Australia. ${ }^{6}$ McKenzie Institute Australia, Beaumaris, Victoria 3193, Australia. ${ }^{7}$ McKenzie Institute International, Raumati Beach 5032, New Zealand. ${ }^{8}$ Physiotherapy Department, Barwon Health, Geelong 3220, Australia. ${ }^{9}$ Sports Injuries Rehabilitation and Prevention for Health Research Unit, The University of Queensland, School of Health and Rehabilitation Sciences, Brisbane, Queensland, Australia.

Received: 22 October 2020 Accepted: 4 May 2021

Published online: 25 May 2021

\section{References}

1. Habets B, van Cingel RE. Eccentric exercise training in chronic mid-portion Achilles tendinopathy: a systematic review on different protocols. Scand J Med Sci Sports. 2015;25(1):3-15. https://doi.org/10.1111/sms.12208.
2. Rio E, Moseley L, Purdam C, Samiric T, Kidgell D, Pearce AJ, et al. The pain of tendinopathy: physiological or pathophysiological? Sports Med. 2014;44(1): 9-23. https://doi.org/10.1007/s40279-013-0096-z.

3. Abate M, Silbernagel KG, Siljeholm C, Di lorio A, De Amicis D, Salini V, et al. Pathogenesis of tendinopathies: inflammation or degeneration? Arthritis Res Ther. 2009;11(3):235. https://doi.org/10.1186/ar2723.

4. Cook JL, Purdam CR. Is tendon pathology a continuum? A pathology model to explain the clinical presentation of load-induced tendinopathy. $\mathrm{Br} J$ Sports Med. 2009;43(6):409-16. https://doi.org/10.1136/bjsm.2008.051193.

5. de Jonge $S$, van den Berg C, de Vos RJ, van der Heide HJ, Weir A, Verhaar $J A$, et al. Incidence of midportion Achilles tendinopathy in the general population. Br J Sports Med. 2011;45(13):1026-8. https://doi.org/10.1136/ bjsports-2011-090342.

6. Turner J, Malliaras P, Goulis J, McAuliffe S. "It's disappointing and it's pretty frustrating, because it feels like it's something that will never go away." a qualitative study exploring individuals' beliefs and experiences of Achilles tendinopathy. PLoS One. 2020;15(5):e0233459. https://doi.org/10.1371/journa I.pone.0233459.

7. Martin RL, Chimenti RL, Cuddeford T, Houck J, Matheson JW, McDonough CM, et al. Achilles pain, stiffness, and duscle power deficits: didportion Achilles tendinopathy revision 2018. JOSPT. 2018;48(5):A1-a38. https://doi. org/10.2519/jospt.2018.0302.

8. Malliaras P, Barton CJ, Reeves ND, Langberg H. Achilles and patellar tendinopathy loading programmes : a systematic review comparing clinical outcomes and identifying potential mechanisms for effectiveness. Sports Med. 2013;43(4):267-86. https://doi.org/10.1007/s40279-013-0019-z.

9. Kingma JJ, de Knikker R, Wittink HM, Takken T. Eccentric overload training in patients with chronic Achilles tendinopathy: a systematic review. Br J Sports Med. 2007;41(6):e3. https://doi.org/10.1136/bjsm.2006.030916.

10. Murphy M, Travers M, Gibson W, Chivers P, Debenham J, Docking S, et al. Rate of improvement of pain and function in mid-portion Achilles tendinopathy with loading protocols: a systematic review and longitudinal meta-analysis. Sports Med. 2018;48(8):1875-91. https://doi.org/10.1007/s402 79-018-0932-2.

11. Mc Auliffe S, Synott A, Casey H, Mc Creesh K, Purtill H, O'Sullivan K. Beyond the tendon: experiences and perceptions of people with persistent Achilles tendinopathy. Musculoskelet Sci Pract. 2017;29:108-14. https://doi.org/10.1 016/j.msksp.2017.03.009

12. Bird SP, Tarpenning KM, Marino FE. Designing resistance training programmes to enhance muscular fitness. Sports Med. 2005;35(10):841-51. https://doi.org/10.2165/00007256-200535100-00002.

13. Bohm S, Mersmann F, Arampatzis A. Human tendon adaptation in response to mechanical loading: a systematic review and meta-analysis of exercise intervention studies on healthy adults. Sports Med Open. 2015;1(1):7. https://doi.org/10.1186/s40798-015-0009-9.

14. Kjaer M. Role of extracellular matrix in adaptation of tendon and skeletal muscle to mechanical loading. Physiol Rev. 2004;84(2):649-98. https://doi. org/10.1152/physrev.00031.2003.

15. Bohm S, Mersmann F, Tettke M, Kraft M, Arampatzis A. Human Achilles tendon plasticity in response to cyclic strain: effect of rate and duration. J Exp Biol. 2014;217(Pt 22):4010-7. https://doi.org/10.1242/jeb.112268.

16. Vicenzino B, de Vos RJ, Alfredson H, Bahr R, Cook JL, Coombes BK, et al. ICON 2019-international scientific Tendinopathy symposium consensus: there are nine CORE health-related domains for tendinopathy (CORE DOMAINS): Delphi study of healthcare professionals and patients. $\mathrm{Br} J$ Sports Med. 2020;54(8):444-51. https://doi.org/10.1136/bjsports-2019-1 00894.

17. McAuliffe S, Tabuena A, McCreesh K, O'Keeffe M, Hurley J, Comyns T, et al. Altered strength profile in Achilles tendinopathy: a systematic review and meta-analysis. J Athl Train. 2019;54(8):889-900. https://doi.org/10.4085/10626050-43-18.

18. Sancho I, Malliaras P, Barton C, Willy RW, Morrissey D. Biomechanical alterations in individuals with Achilles tendinopathy during running and hopping: a systematic review with meta-analysis. Gait \& Posture. 2019;73: 189-201. https://doi.org/10.1016/j.gaitpost.2019.07.121.

19. Hasani F, Haines T, Munteanu SE, Vicenzino B, Malliaras P. Efficacy of different load intensity and time-under-tension calf loading protocols for Achilles tendinopathy (the LOADIT trial): protocol for a randomised pilot study. Pilot Feasibility Stud. 2020;6(1):99. https://doi.org/10.1186/s40814-020-00639-5.

20. Eldridge SM, Chan CL, Campbell MJ, Bond CM, Hopewell S, Thabane L, et al. CONSORT 2010 statement: extension to randomised pilot and feasibility 
trials. Pilot Feasibility Stud. 2016;2(1):64. https://doi.org/10.1186/s40814-016 0105-8.

21. Hoffmann TC, Glasziou PP, Boutron I, Milne R, Perera R, Moher D, et al. Better reporting of interventions: template for intervention description and replication (TIDieR) checklist and guide. BMJ. 2014;348(mar07 3):g1687. https://doi.org/10.1136/bmj.g1687.

22. Magnusson SP, Hansen M, Langberg H, Miller B, Haraldsson B, Westh EK, et al. The adaptability of tendon to loading differs in men and women. Int J Exp Pathol. 2007;88(4):237-40. https://doi.org/10.1111/j.1365-2613.2007. 00551.x.

23. Murphy M, Rio E, Debenham J, Docking S, Travers M, Gibson W. Evaluating the progress of mid-portion Achilles tendinopathy during rehabilitation: a review of outcome measures for muscle structure and function, tendon structure, and neural and pain associated mechanisms. Int I Sports Phys Ther. 2018;13(3):537-51. https://doi.org/10.26603/ijspt20180537.

24. administration Tg: Recommended paracetamol doses. In. Canberra; 2013.

25. Silbernagel KG, Thomee R, Eriksson BI, Karlsson J. Full symptomatic recovery does not ensure full recovery of muscle-tendon function in patients with Achilles tendinopathy. Br J Sports Med. 2007;41(4):276-80; discussion 280. https://doi.org/10.1136/bjsm.2006.033464.

26. Keech AC, Wonders SM, Cook DI, Gebski VJ. Balancing the outcomes: reporting adverse events. Med J Aust. 2004;181(4):215-8. https://doi.org/10. 5694/j.1326-5377.2004.tb06241.x.

27. Reilly MC, Zbrozek AS, Dukes EM. The validity and reproducibility of a work productivity and activity impairment instrument. Pharmacoeconomics. 1993; 4(5):353-65. https://doi.org/10.2165/00019053-199304050-00006.

28. Average Weekly Earnings, Australia. https://www.abs.gov.au/statistics/la bour/earnings-and-work-hours/average-weekly-earnings-australia/latest-relea se\#keystatistics. Accessed Nov 2020.

29. Robinson JM, Cook JL, Purdam C, Visentini PJ, Ross J, Maffulli N, et al. The VISA-A questionnaire: a valid and reliable index of the clinical severity of Achilles tendinopathy. Br J Sports Med. 2001;35(5):335-41. https://doi.org/1 0.1136/bjsm.35.5.335.

30. Scott W, McCracken LM. Patients' impression of change following treatment for chronic pain: global, specific, a single dimension, or many? J Pain. 2015; 16(6):518-26. https://doi.org/10.1016/j.jpain.2015.02.007.

31. Maksymowych WP, Richardson R, Mallon C, van der Heijde D, Boonen A. Evaluation and validation of the patient acceptable symptom state (PASS) in patients with ankylosing spondylitis. Arthritis Rheum. 2007;57(1):133-9. https://doi.org/10.1002/art.22469.

32. Sallis JF, Haskell WL, Wood PD, Fortmann SP, Rogers T, Blair SN, et al. Physical activity assessment methodology in the five-city project. Am J Epidemiol. 1985;121(1):91-106. https://doi.org/10.1093/oxfordjournals.a je.a113987.

33. Houben RM, Leeuw M, Vlaeyen JW, Goubert L, Picavet HS. Fear of movement/injury in the general population: factor structure and psychometric properties of an adapted version of the Tampa scale for kinesiophobia. J Behav Med. 2005;28(5):415-24. https://doi.org/10.1007/s1 0865-005-9011-x.

34. Sullivan MJLBS, Pivik J. The pain catastrophizing scale: development and validation. Psychol Assess. 1995;7(4):524-32. https://doi.org/10.1037/1040-3 590.7.4.524.

35. Freynhagen R, Baron R, Gockel U, Tolle TR. painDETECT: a new screening questionnaire to identify neuropathic components in patients with back pain. Curr Med Res Opin. 2006;22(10):1911-20. https://doi.org/10.1185/03 $0079906 \times 132488$.

36. Julious SA. Sample size of 12 per group rule of thumb for a pilot study. Pharmaceut Statist. 2005;4(4):287-91. https://doi.org/10.1002/pst.185.

37. A new view of statistics. 2016. http://sportsci.org/resource/stats.

38. Mentiplay BF, Perraton LG, Bower KJ, Adair B, Pua YH, Williams GP, et al. Assessment of lower limb muscle strength and power using hand-held and fixed dynamometry: a reliability and validity study. PLoS One. 2015;10(10): e0140822. https://doi.org/10.1371/journal.pone.0140822.

39. Mentiplay BF, Tan D, Williams G, Adair B, Pua YH, Bower KJ, et al. Assessment of isometric muscle strength and rate of torque development with hand-held dynamometry: test-retest reliability and relationship with gait velocity after stroke. J Biomech. 2018;75:171-5. https://doi.org/10.1016/j. jbiomech.2018.04.032.

40. Little RJA. A test of missing completely at random for multivariate data with missing values. JASA. 1988:83(404):1198-202. https://doi.org/10.1080/016214 59.1988.10478722
41. van Leeuwen MT, Blyth FM, March LM, Nicholas MK, Cousins MJ. Chronic pain and reduced work effectiveness: the hidden cost to Australian employers. Eur J Pain. 2006;10(2):161-6. https://doi.org/10.1016/j.jpain.2005. 02.007.

42. Beyer R, Kongsgaard M, Hougs Kjaer B, Ohlenschlaeger T, Kjaer M, Magnusson SP. Heavy slow resistance versus eccentric training as treatment for Achilles tendinopathy: a randomized controlled trial. Am J Sports Med. 2015;43(7):1704-11. https://doi.org/10.1177/0363546515584760.

43. Sancho I, Morrissey D, Willy RW, Barton C, Malliaras P. Education and exercise supplemented by a pain-guided hopping intervention for male recreational runners with midportion Achilles tendinopathy: a single cohort feasibility study. Phys Ther Sport. 2019;40:107-16. https://doi.org/10.1016/j. ptsp.2019.08.007.

44. Helms ER, Cronin J, Storey A, Zourdos MC. Application of the repetitions in reserve-based rating of perceived exertion scale for resistance training. Strength Cond J. 2016;38(4):42-9. https://doi.org/10.1519/SSC. 0000000000000218

45. Munteanu SE, Scott LA, Bonanno DR, Landorf KB, Pizzari T, Cook JL, et al. Effectiveness of customised foot orthoses for Achilles tendinopathy: a randomised controlled trial. Br J Sports Med. 2015;49(15):989-94. https://doi. org/10.1136/bjsports-2014-093845.

46. Silbernagel KG, Thomeé R, Eriksson BI, Karlsson J. Continued sports activity, using a pain-monitoring model, during rehabilitation in patients with Achilles tendinopathy: a randomized controlled study. Am J Sports Med. 2007;35(6):897-906. https://doi.org/10.1177/0363546506298279.

47. Higgins J, Thomas J, Chandler J, Cumpston M, Li T, Page MJ, et al. Cochrane handbook for systematic reviews of interventions version 6.0 (updated July 2019). The Cochrane Collaboration; 2019.

48. Yelland MJ, Sweeting KR, Lyftogt JA, Ng SK, Scuffham PA, Evans KA. Prolotherapy injections and eccentric loading exercises for painful Achilles tendinosis: a randomised trial. Br J Sports Med. 2011;45(5):421-8. https://doi. org/10.1136/bjsm.2009.057968.

\section{Publisher's Note}

Springer Nature remains neutral with regard to jurisdictional claims in published maps and institutional affiliations.

Ready to submit your research? Choose BMC and benefit from:

- fast, convenient online submission

- thorough peer review by experienced researchers in your field

- rapid publication on acceptance

- support for research data, including large and complex data types

- gold Open Access which fosters wider collaboration and increased citations

- maximum visibility for your research: over $100 \mathrm{M}$ website views per year

At BMC, research is always in progress.

Learn more biomedcentral.com/submissions 